\title{
REFLEXÕES SOBRE ENSINO E PESQUISA EM HISTÓRIA INDÍGENA NO PARÁ E EM MINAS GERAIS*
}

\author{
Gefferson Ramos Rodrigues ${ }^{1}$
}

\section{Aproximações}

Em princípio, atuar no ensino de história na Amazônia, onde ingressei em 2017 como professor do curso de História da Universidade Federal do Oeste do Pará (Ufopa), não me fez refletir de imediato sobre uma possível comparação com a docência em Minas Gerais, onde realizei parte de minha formação. Devo admitir, isso só me veio com o convite dos organizadores deste livro e, procurando ser fiel à proposta da obra, farei o relato dessa experiência. Até mesmo o formato do próprio texto é inédito para mim, habituado aos impessoais escritos mais essencialmente acadêmicos, embora este, em certa medida, não o deixe de ser; o relato será feito em primeira pessoa, algo a que estou pouco acostumado.

O termo relato não é mera força de expressão, mas tem o sentido de descrever a atividade, já que, embora não destituído de reflexão, pretende contar a experiência de docência da disciplina História Indígena, lecionada nos anos 2017 e 2018 no curso de História da Ufopa. Escrevo este capítulo como professor especialista em história moderna e história do Brasil colônia, e, embora a área de minha especialidade pareça algo distante do tema "história indígena", esse distanciamento é apenas aparente. Em minha dissertação de mestrado e, sobretudo, em minha tese de doutorado, tive a oportunidade de tratar do assunto.

Em meu trabalho de dissertação, estudei uma série de levantes ocorridos no sertão do rio São Francisco em Minas Gerais ao longo do ano 1736 (Rodrigues, 2009). Os protestos tiveram uma composição social diversificada, contando com a habitual presença de elites locais, mas também de escravos, libertos, mestiços, homens livres pobres e, o que aqui interessa mais de perto, de indígenas. Durante os levantes no sertão, os índios tiveram atuação fundamen-

\footnotetext{
*DOI - 10.29388/978-65-86678-64-2-0-f.137-152

1 Professor adjunto do curso de História da Universidade Federal do Oeste do Pará (Ufopa), Campus de Santarém. Graduado em História pela Universidade Estadual de Montes Claros (Unimontes). Mestre e doutor em História pela Universidade Federal Fluminense (UFF).
} 
tal. Foram eles uma das principais forças dos rebeldes para enfrentar as tropas da Coroa. Isso não significa dizer que seu papel fosse reduzido apenas ao de "braço armado" dos senhores proprietários de terras.

Durante as pesquisas, fui instado a aprofundar o que havia levado os indígenas a lutar ao lado de grandes proprietários. Embora estivesse estudando um evento ocorrido em um ano específico — 1736 —, avanços e recuos são sempre necessários. Ao recuar um pouco mais as pesquisas e investigar o processo de ocupação do sertão, deparei-me com a existência da Missão do Sr. João do Riacho do Itacarambi, criada em 1728 em localidade muito próxima do palco dos eventos. Em princípio, não ficara evidente a ligação entre os índios da missão e a revolta, mas, com o aprofundamento das investigações, encontrei referência direta.

A Missão do Sr. João deu origem à atual cidade de São João das Missões, no Norte de Minas Gerais. Do mesmo modo, Santarém, no oeste do Pará, tem sua origem relacionada com o estabelecimento de uma missão, a Missão dos Tapajós.

Pode parecer forçoso, principalmente para um historiador da colônia, tentar alguma aproximação entre o Pará e Minas Gerais no século XVIII, claro, já que, enquanto Minas só se constituiu basicamente no Setecentos, o Pará já contava com a presença de colonizadores desde as primeiras décadas do Seiscentos. Outra diferença marcante é a de que, enquanto Minas abrigou o maior número de escravos africanos na colônia, o Pará contou com contingente expressivo de população indígena. Diante dessas diferenças, pode ser até mesmo irônico que um dos profícuos campos de estudo na historiografia mineira atualmente seja o da história indígena, ao passo que um dos temas mais estudados entre os historiadores do Pará nos últimos anos é justamente o da escravidão africana. $^{2}$

Ao longo do mestrado, percebi que escravos, índios e homens livres pobres estiveram presentes não apenas nas contestações do sertão, e no doutorado procurei desenvolver melhor o assunto (Rodrigues, 2015). Assim, busquei estudar a participação de índios na "Guerra dos Mascates", em 1710-1711, a conspiração escrava em Minas Gerais, em 1719, e a revolta dos soldados na Bahia, em 1728. Um dos objetivos foi o de reconstituir esses movimentos a partir de seus próprios protagonistas. Enfatizando aqui, a participação dos indígenas, o papel dos grupos nativos na "Guerra dos Mascates" foi significativo. Ao

\footnotetext{
${ }^{2}$ Para um exemplo, no caso de Minas Gerais, ver: Resende (2003). Sobre a escravidão na Amazônia, consultar o verbete e as referências ali citadas para uma aproximação com o tema: Gomes (2018, p. 106-112).
} 
término do conflito, eles foram saudados vivamente pelas ruas do Recife como sinal de reconhecimento.

A história indígena é tema cada vez mais frequente na agenda dos historiadores no Brasil, embora sempre o fosse entre os historiadores da América espanhola (Monteiro, 2001). O motivo dessa diferença pode parecer evidente, em razão de a escravidão africana ter sido estrutural na América portuguesa, ao passo que a escravidão indígena, decisiva na América espanhola. Fato é que os historiadores só foram dedicar-se ao assunto em data bem recente. Antes disso, julgava-se, erroneamente, ser tarefa de antropólogos e sociólogos, enquanto, nos países de colonização espanhola, o assunto já está há muito na pauta dos estudiosos da história (Almeida, 2003, 2010). Independentemente se historiadores e antropólogos mostraram-se mais ou menos dedicados em um ou outro lugar, a história indígena terá de ser sempre interdisciplinar (Almeida, 2003, 2010). Vê-se até mesmo o surgimento de um novo campo de estudos, qual seja, o da etno-história. Esse é, aliás, um ganho imenso para ambas as disciplinas e, como atestam os trabalhos mais recentes, um caminho sem volta. É importante os historiadores adotarem uma abordagem com a antropologia, enquanto se considera necessário os antropólogos darem uma dimensão histórica às suas obras. Essa relação, sempre salutar, precisa, no entanto, estar atenta a algumas diferenças. $\mathrm{O}$ historiador trabalha com diacronia, ao passo que o antropólogo, com sincronia. Nas palavras de Evaldo Cabral de Mello (2015): "o interesse do historiador começa onde termina o do sociólogo", e, por extensão, o do antropólogo.

Em razão dessa simbiótica relação entre história e antropologia, surgiu o que se passou a chamar de "nova história indígena" (Almeida, 2012, p. 151168). O "nova", aqui — vale ressaltar —, não é necessariamente para desqualificar tudo o que se fez antes, mas, sim, para evidenciar o diálogo com outras disciplinas, notadamente com a antropologia, mas também com a arqueologia, a linguística etc. A "nova história indígena" não sugere que os historiadores de gerações passadas devam ser simplesmente evitados. Pelo contrário, precisam ser lidos ou relidos com olhar ainda mais crítico. Ainda que eivados de etnocentrismo, deram contribuição de interesse para os estudiosos de hoje, especialmente pelo trabalho etnográfico que realizaram. 


\section{O sertão do São Francisco e o sertão da Amazônia}

Um conceito importante para contrastar Minas Gerais e Amazônia é o de sertão. Na definição de Capistrano de Abreu, existe um "sertão de dentro" e um "sertão de fora", ou seja, um que se comunica com o litoral e outro mais voltado para si próprio (Abreu, 1976). É esse "sertão de dentro", com poucos contatos com o mundo exterior, que se estende pelo interior de Pernambuco, Bahia e Minas Gerais, acompanhando basicamente o curso do rio São Francisco, que será tratado aqui.

Para os habitantes dessa vasta área de poucas chuvas, terra árida, clima seco e quente, é até mesmo difícil imaginar que a densa floresta amazônica também fosse considerada sertão. Isso, no entanto, faz todo sentido, se se remeter a um dos significados que o termo comporta, qual seja, o sertão seria a corruptela de "desertão", o espaço do vazio, desabitado, despovoado. Sabe-se que, no caso da Amazônia, a floresta era habitada por diversos povos indígenas, e considerá-la sertão era um modo de justificar sua ocupação (Chamboleyron, 2010). No sertão do São Francisco, não era muito diferente; sabia-se da existência dos indígenas, mas os colonizadores não tinham, em princípio, o interesse de se fixar (Santos, 2009).

O sertão de onde veio a ser Minas Gerais era, conforme expressão de época, lugar onde os paulistas iam, com sua "auri sacra famis", "buscar o remédio para sua miséria". A principal fonte de riqueza era, efetivamente, a mão de obra indígena, muito mais que a busca de riquezas minerais (Monteiro, 1994). A descoberta de minérios era atividade dispendiosa e envolvia grande soma de recursos e conhecimentos técnicos, nem sempre disponíveis (Holanda, 1985a, p. 228-310). A Coroa portuguesa, que tanto estimulou expedições para a descoberta de metais e pedras preciosas, viu seus objetivos frustrados em muitos momentos, quando os desbravadores, em vez de irem à cata de riquezas minerais, na verdade saíam à procura de índios (Souza, 2006). Se os homens do planalto paulista demonstraram grande capacidade para explorar áreas inóspitas e hostis, o mesmo não se pode dizer em relação ao "sertão" amazônico. A colonização na Amazônia foi feita por degredados, desertores, condenados da justiça, mas longe se está aqui de considerar que a ocupação europeia da floresta fora feita pelo pior tipo de gente que havia no Reino (Souza Jr., 2012).

Uma das principais atividades a que se dedicavam as pessoas que troca-

vam o Velho pelo Novo Mundo, especialmente na Amazônia, era a busca da mão de obra indígena e, principalmente, das chamadas "drogas do sertão". 


\section{História indigenista}

Até a primeira metade do século XVI, os índios foram principalmente parceiros comerciais dos europeus, trocando pau-brasil por foices, machados e facas - objetos que lhes eram de interesse. A partir do estabelecimento do Governo Geral, em 1549, e do aprofundamento dos interesses da Coroa portuguesa na América, as relações com os índios tornaram-se mais complexas. Governo, colonos e missionários ora se conformavam, ora se confrontavam em relação ao trato com os indígenas. De todo modo, os índios já não eram mais os parceiros comerciais de antes. Agora, a partir de meados do século XVI, com a necessidade de desenvolver o empreendimento colonial, eles se converteram na principal fonte de mão de obra, mas também em soldados, para combater índios não aliados e dar cobro aos estrangeiros que ameaçavam o domínio português na América (Cunha, 2009).

Em linhas gerais, essa situação perdurou até meados do século XVII, quando os portugueses livraram-se do domínio de Espanha. A partir daí, houve grande incremento no número de missões, especialmente na Amazônia, com destaque para a atuação dos jesuítas (Cunha, 2008).

Nas aldeias, os índios eram catequisados, tinham de ser bem tratados, deveriam ser livres, proprietários das terras, trabalhar na produção de gêneros de subsistência, podendo ainda ser solicitados no trabalho para os colonos, mas mediante pagamento de salários (Perrone-Moisés, 2008, p. 117-118). Sua incorporação à aldeia era feita principalmente por meio dos chamados "descimentos", ou seja, o deslocamento dos índios do sertão para aldeamentos próximos das povoações, onde seriam "reduzidos" - em outros termos, submetidos ao cativeiro (Vainfas, 2001, p. 21-24; Domingues, 2000). Além de religiosos, leigos também chegaram a administrar as aldeias - sobretudo na segunda metade do século XVIII —, mas, enquanto os civis queriam somente submetê-los ao trabalho forçado, os eclesiásticos pretendiam principalmente catequizá-los (Vainfas, 2001, p. 21-24; Domingues, 2000).

O grande poder amealhado pela ordem jesuíta incomodou Sebastião José de Carvalho e Melo, marquês de Pombal, que os expulsou de Portugal e seus domínios em 1759, não sem antes implementar o "Diretório dos Índios", em 1757, transferindo as aldeias da tutela religiosa para autoridades leigas (Vainfas, 2001, p. 21-24; Domingues, 2000; Almeida, 1997).

Daí em diante, não havia mais opositores, quando se tratava escravizar os índios e avançar sobre suas terras. Mas, foi sobretudo a partir de meados do século XIX que o interesse das elites senhoriais deslocou-se do trabalho para as 
terras indígenas (Cunha, 2008). "Um século mais tarde", como notou Manuela Carneiro da Cunha, "deslocar-se-á novamente: do solo, passará para o subsolo indígena” (Cunha, 2008, p. 16).

\section{Indígenas na história}

Em consonância com as políticas de governo da época, que procuraram garantir maior acesso a índios, pardos, negros e estudantes provenientes de escola pública, a Ufopa foi criada em 2009 - resultado do aproveitamento dos antigos campi da Universidade Federal do Pará (UFPA) e da Universidade Federal Rural da Amazônia (UFRA) —, com entrada especial para grupos menos favorecidos. Na universidade, dois dos cursos mais concorridos para os índios, em especial, são Direito e Antropologia, cursos do Instituto de Ciências da Sociedade (ICS). No Instituto de Ciências da Educação (Iced), existem os cursos de Biologia, Química, Letras, Pedagogia, Física e Matemática (integrados), mas História, Geografia e Pedagogia são os que mais recebem alunos indígenas (Gois e Sousa, 2015, p. 181, e 2017, p. 113-131). Os estudantes indígenas recebem bolsa-permanência do Fundo Nacional de Desenvolvimento da Educação (FNDE) e auxílio adicional da Ufopa.

A maioria das populações indígenas que vive no Baixo Amazonas está localizada ao longo do rio Tapajós e de seus afluentes, a exemplo dos rios Maró e Arapiuns. Algumas aldeias aí estabelecidas têm sua origem ligada a antigos aldeamentos jesuítas, fundados ainda nos séculos XVII-XVIII (Menéndez, 2008, p. 289). Atualmente, existem no Baixo Amazonas 48 comunidades que se assumem como indígenas, pertencentes a 12 povos: Apiaká, Borari, Maytapu, Munduruku, Cara Preta, Tupinambá, Cumaruara, Arapium Jaraqui, Tapajó, Tupaiu e Arara Vermelha, em uma estimativa de 7 mil indígenas (Vaz, 2011, p. 423).

Tão logo comecei a ministrar a disciplina História Indígena e do Indigenismo, um aluno me procurou para orientá-lo, o que aceitei prontamente. Depois dele, vários outros vieram, até mesmo alguns para os quais eu ainda não havia dado aula. Considerei que isso não era atitude isolada, mas que eles se comunicavam entre si. Em razão de meu interesse de pesquisa pela questão indígena - embora, é importante reforçar, pelo "índio colonial" —, acredito que isso tenha feito com que me procurassem meio que como um "movimento".

Enquanto ministrei a disciplina, tive alunos Wai Wai, Kaxuyana, Arapium, Tupinambá e Tupaiu. 
Não seria possível, no limite destas páginas, realizar análises mais aprofundadas de cada um deles, e a respeito de alguns existe farta bibliografia. Para as informações aqui presentes, recorri essencialmente ao site do Instituto Socioambiental, referência essencial no assunto. Apesar da abordagem um tanto panorâmica, o objetivo é somente destacar alguns dos aspectos que provocaram reflexões em um professor recém-chegado à Amazônia e que se vê diante de questões que o levam a repensar sua pedagogia e práticas de pesquisa. No limite, o texto poderá ser útil para eventual interessado em saber sobre as primeiras impressões de um professor ao se deparar com uma realidade completamente diferente da sua.

Entre os Wai Wai, tive dois orientandos; o primeiro, Denis Wai Wai, e outro, com trabalho ainda em andamento, Tewtasa Wai Wai. Os Wai Wai vivem entre a Guiana Inglesa e o Brasil. ${ }^{3}$ No Brasil, ocupam terras indígenas já demarcadas. São elas: Nhamundá-Mapuera, entre Pará e Roraima; TrombetasMapuera, entre Roraima, Pará e Amazonas; e, por fim, a terra indígena Wai Wai, em Roraima. Falam o Wai Wai, da família linguística Karib (Zea, s. d.). Os alunos Wai Wai na Ufopa são provenientes da aldeia Mapuera, localizada às margens dos rios Mapuera e Trombetas, relativamente próxima da cidade de Oriximiná; de Santarém até Mapuera, estimam-se cerca de sete dias de viagem de barco.

A comunidade reúne membros das etnias Katuena, Hixkaryana, Xerew, Karapayana, do mesmo tronco linguístico, e alguns de família Arawak, como os Mawayana (Zea, s. d.).

O histórico do contato com os Wai Wai remonta ao século XVII, com a passagem de Harcout, em 1603, e ao século XVIII, com Sanders, em 1721. No século seguinte, vários viajantes estrangeiros tiveram contato com eles: o geógrafo inglês Robert Hermann Schomburgk (1835-1839 e 1843), o geólogo britânico Barrington Brown (1876 e 1878), Henri Coudreau (1899) e Olga Coudreau (1900). Nas primeiras décadas do século XX, os Wai Wai foram visitados por diversos estrangeiros, sem sofrerem grandes transformações. Isso pelo menos até a década de 1950, quando permitiram o estabelecimento da Unevangelized Fields Mission (UFM - Cruzada de Avangelização Mundial, na sigla em inglês). Integrada por três irmãos norte-americanos, Neil, Rader e Robert Hawkins, procurou atrair a maior parte deles para a Guiana Inglesa. Antes dis-

${ }^{3} \mathrm{Na}$ Guiana, eles estão em duas aldeias: a primeira delas, a aldeia Masakinyari, com população variante entre 130 e 170 habitantes, e a segunda, a aldeia Parabara, com aproximadamente 70 habitantes (Zea, s. d.). 
so, Neil e Rader conviveram 10 anos com os Macuxi em Rio Branco, no Acre (Zea, s. d.).

Nos relatos, os estrangeiros são unânimes em destacar a característica de viajantes dos Wai Wai, que se deslocavam em grandes distâncias para contatar povos nunca vistos. São conhecidos como exímios caçadores, muito hábeis no estabelecimento de trocas com outros grupos indígenas.

Oferecendo-lhes anzóis, espelhos, facas e miçangas — artefatos apreciados pelos índios - e pregações com promessas de vida melhor, os irmãos missionários tentaram atraí-los para a Guiana Inglesa. Utilizando-se desses estratagemas, conseguiram atrair rapidamente grande número deles e fundaram na Guiana a aldeia Kanashen (Deus ama você aqui). Para que alcançassem esse resultado, em muito se valeram da colaboração do cacique Ewka, xamã e grande líder entre os Wai Wai. Depois de ter sido convertido, Ewka tornou-se também um missionário em favor do projeto dos irmãos norte-americanos.

Em 1971, por motivações políticas, a Missão Kanashen foi expulsa da Guiana, e os índios dispersam-se, permanecendo apenas um pequeno número na área, enquanto outros migraram para o Suriname, e a maior parte veio para o Brasil. Os missionários, então, passaram a acompanhar os índios no lado brasileiro, integrando-se à Missão Evangélica da Amazônia (Meva) e à Missão Cristã Evangélica do Brasil (Miceb) (Zea, s. d.).

Entre os anos 1950 e 1980, os Wai Wai passaram por um processo de centralização em grandes aldeias. Isso trouxe consequências. Como resultado, levou a uma escassez de recursos, fazendo com que muitos passassem a migrar para suas áreas de origem, voltando a cultivar, inclusive, suas línguas maternas, a exemplo dos Hixcaryana, Karapayana, Katuena e Xerew (Zea, s. d.).

Denis Teeni Wai Wai ingressou na Ufopa em 2013. Em seu trabalho de conclusão de curso (TCC), tratou das dificuldades enfrentadas na universidade pelos alunos indígenas de sua etnia, bem como fez apontamentos para que a instituição se tornasse mais inclusiva (Wai Wai, D., 2018). Outro orientando, na verdade com trabalho ainda em curso, é Tewtasa Wai Wai. Ele trata da migração dos Wai Wai da Guiana Inglesa para o Brasil por meio da memória dos anciãos da aldeia Mapuera, onde foi criado (Wai Wai, T., 2018). A distância de sete dias de viagem é algo que realmente surpreende o observador mais desavisado. Todavia, percorrer essa grande distância para estudar não deixa, de certo modo, de estar ligado à própria característica do povo Wai Wai, conhecido desde os mais remotos relatos de viajantes do século XVII até os mais recentes do século XX — como percorredor de grandes distâncias. Isso, penso eu, não 
deixa de apontar o grande desprendimento desse povo para o estabelecimento de contatos com povos diversos.

Entre os Wai Wai, também chegaram a conviver os Kaxuyana, e muitos casaram-se entre si. Uma delas foi Neide Kaxuyana. ${ }^{4}$ Todavia, os Kaxuyana chamam a si mesmos de Purehno. Têm língua própria, ainda falada entre eles, do grupo linguístico da família Karib. O termo pelo qual se tornaram mais conhecidos quer dizer habitantes (yana) do rio Cachorro (Kaxuru), um afluente no curso médio rio Trombetas, oeste do Pará, próximo às cidades de Óbidos e Oriximiná. Na realidade, Kaxuyana é uma designação genérica - semelhante ao caso dos Wai Wai —, e o termo inclui outros povos, como os Kahuyana, os Yaskuriyana, entre outros, embora historicamente estejam todos ligados entre si.

Os Kaxuyana encontram-se em três áreas distintas. Em sua terra de origem, às margens do Rio Cachorro, afluente que deságua no curso médio do rio Trombetas, ao noroeste do estado do Pará; na região dos rios Nhamundá e Mapuera, juntamente com os Waiwai e Hixkariyana, no extremo oeste do estado do Pará e na Terra Indígena Parque do Tumucumaque, juntamente com os Tiriyó, no extremo norte do estado do Pará. (Grupioni, s. d.).

Todos esses povos vivem em afluentes do rio Trombetas e, segundo dados de 2010, atualmente são em número de 350 pessoas. Embora seja oficialmente um grupo étnico, os Kaxuyana ainda não tiveram sua terra demarcada, que se encontra em processo de regularização fundiária (Grupioni, s. d.).

Mais próximos de Santarém estão os Arapiuns, que vivem nas terras indígenas Maró e Cobra Grande. A primeira fica nos rios Aruã e Maró, cabeceiras do rio Arapiuns, afluente da margem direita do Amazonas, boca do rio Tapajós; a segunda fica à margem esquerda do rio Arapiuns. Alguns ainda vivem em áreas urbanas, como em Vila Franca e Santarém. Eles falam Sateré-Mawé, do grupo linguístico Tupi, além do Nheengatu, língua franca criada pelos jesuítas para comunicação na Amazônia.

Parte dos Arapiuns vive com os Borari, e, em dezembro de 2014, um juiz federal decretou que eles eram povos ribeirinhos, e não índios propriamente ditos, portanto não teriam direito ao território delimitado pela Fundação Na-

${ }^{4}$ Ver: Kaxuyana (2018). 
cional do Índio (Funai). O Ministério Público Federal suspendeu a sentença, embargando, assim, a permissão para entrada de madeireiros. ${ }^{5}$

Não é demais lembrar que Santarém é uma cidade estratégica para o agronegócio. Essa pressão sobre a floresta para o plantio de monocultura uma herança colonial, sem dúvida - é vivenciada pelo Sr. Roberto da etnia Arapium, que nos relatou durante as aulas o forte interesse dos madeireiros sobre suas terras.

Outra a me procurar para ser seu orientador foi Patrícia Tupinambá, de quem também fui professor. Desde o século XVI, tanto os Tupinambás quanto os Tapajós são grupos referidos nas crônicas coloniais como povos com alta densidade demográfica. Estima-se que os Tapajós tenham estendido sua influência pela margem esquerda do rio de mesmo nome por cerca de $180 \mathrm{~km}^{2}$. Os cronistas de época ressaltam ainda que esses dois grupos tinham intenso contato entre si. Conforme as fontes disponíveis, tudo indica que os Tapajós e os Tupinambás passaram por um processo de expansão até a primeira metade do século XVII, mas essa expansão arrefeceu-se pelo contato com os brancos, de modo que, no final do Seiscentos, "pouco restava da populosa aldeia situada na foz do Tapajós, e nesse tempo já não se fala mais dos Tupinambás como etnia” (Menéndez, 2008, p. 282).

Muitas comunidades indígenas do Baixo Amazonas recorrem, ainda hoje, à memória da participação naquela que foi a maior rebelião camponesa da história do Brasil, a Cabanagem (1835-1839), , quando se trata de reivindicar direitos sobre as terras que ocupam. Quando se fala de participação indígena na revolta, não se deve imaginar um posicionamento "em bloco", como se todos os índios indistintamente tivessem se posicionado de uma única maneira no movimento rebelde. Existiram índios a favor e contra os cabanos. Mas, vale observar, os índios ao lado das tropas legalistas foram minoria. Os índios que se juntaram aos rebeldes foram principalmente índios considerados "errantes" pelas autoridades, ou seja, os que escapavam aos trabalhos impostos pelos proprietários brancos e que, embora livres, exerciam atividades que pouco se diferenciavam da escravidão. Por outro lado, os índios que trabalhavam junto às povoações, mais influenciados pelas autoridades, lutaram contra os cabanos em favor dos legalistas (Menéndez, 2008, p. 282).

5 JUSTIÇA do Pará considera etnias Borari e Arapium como índios verdadeiros. Agência Brasil. Brasília, 6 mar. 2015. Disponível em:

< http://agenciabrasil.ebc.com.br/geral/noticia/2015-03/justica-do-para-consideraetnias-borari-e-arapium-como-indios-verdadeiros. > Acesso em: 29 maio 2019.

${ }^{6}$ Para uma historiografia sobre a Cabanagem, ver: Ricci (2001, p. 241-271). O estudo mais recente sobre o tema é de Harris (2017). 
A Cabanagem, por toda a sua extensão e complexidade, ajuda a entender outros movimentos correlatos em outros tempos e lugares.

\section{Encontros e convergências}

Umas das experiências mais significativas ao lecionar História Indígena na Amazônia é efetivamente a oportunidade de trabalhar com alunos indígenas.

A experiência com o ensino na Amazônia levou-me a fazer reflexões não apenas sobre minha prática docente, mas também sobre minhas atividades de pesquisa. Em relação a esta, um dos aspectos a ressaltar é o ponto em comum entre a área que privilegiei em meus estudos no sertão do São Francisco, em Minas Gerais, e o Baixo Amazonas, no Pará, qual seja, o processo de ocupação deu-se a partir do estabelecimento de missões. No caso do sertão, ainda existiram outras unidades de ocupação, como fazendas de gado, igrejas, entre outras (Santos, 2009). Em Minas, por excelência, a principal unidade de ocupação, de maneira geral, foi o estabelecimento de vilas. A descoberta de ouro fazia com que áreas rapidamente ocupadas fossem logo elevadas à condição de vila, com a finalidade de a Coroa portuguesa exercer maior controle sobre elas (Fonseca, 2011). A criação de vilas no Baixo Amazonas só ocorreria na segunda metade do século XVIII. A partir do estabelecimento do Diretório Pombalino, as antigas missões jesuítas foram rapidamente convertidas em vilas (Domingues, 2000). As missões, por muito tempo vistas como algo que degradava a cultura dos índios, mais recentemente foram reinterpretadas como lugares de reconfiguração de identidades. Os indígenas, antes vivendo em suas aldeias, ao serem descidos para os aldeamentos missionários, passaram mais tarde a assumir uma nova identidade, qual seja, a identidade de índio missionário (Almeida, 2003, 2010).

Esse é um processo que se observa nas duas áreas aqui em análise. A Missão do Sr. São João, em Minas Gerais, converteu-se na atual cidade de São João das Missões. No Baixo Amazonas, cidades como Santarém, antigos aldeamentos jesuítas, passaram pelo mesmo processo.

Com efeito, a Cabanagem ajuda na compreensão dos levantes do sertão. A participação dos índios na revolta do sertão foi pouco problematizada pelos estudos que se realizaram até então. Em minha dissertação, defendi que eles, mesmo lutando ao lado de grandes proprietários, conseguiram preservar sua autonomia, especialmente no que diz respeito à conservação de suas terras, sob seu controle até os dias de hoje. Em São João das Missões, os índios conse- 
guem eleger vereadores, prefeitos e até deputado. No Pará, a memória da Cabanagem ainda é ativada, quando se trata de reivindicar melhores condições de vida para suas populações.

\section{Referências}

ABREU, J. Capistrano de. Capitulos de história colonial: 1500-1800. Prefácio de José Honório Rodrigues. 6. ed. anotada. Rio de Janeiro: Civilização Brasileira; Brasília: INL, 1976.

ALMEIDA, Maria Regina Celestino de. História e antropologia. In: CARDOSO, Ciro Flamarion; VAINFAS, Ronaldo (org.). Novos dominios da história. Rio de Janeiro: Campus, 2012.

ALMEIDA, Maria Regina Celestino de. Metamorfoses indigenas: identidade e cultura nas aldeias coloniais do Rio de Janeiro. Rio de Janeiro: Arquivo Nacional, 2003.

. Os indios na história do Brasil. Rio de Janeiro: FGV, 2010. (Coleção FGV de bolso. Série História).

ALMEIDA, Rita Heloísa de. O Diretório dos índios: um projeto de civilização no Brasil do século XVIII. Brasília: UNB, 1997.

CHAMBOLEYRON, Rafael. Povoamento, ocupaşão e agricultura na Amazônia colonial (1640-1706). Belém: Açai: UFPA, 2010.

CUNHA, Manuela Carneiro da. Imagens de índios do Brasil no século XVI. In: Cultura com aspas e outros ensaios. São Paulo: Cosac Naify, 2009.

- Introdução a uma história indígena. In: CUNHA, Manuela Carneiro da (org.). História dos indios no Brasil. [1. ed., 1992]. 2. ed. São Paulo: Companhia das Letras: Secretaria Municipal de Cultura: Fapesp, 2008.

DOMINGUES, Ângela. Quando os indios eram vassalos: colonização e relações de poder no norte do Brasil na segunda metade do século XVIII. Lisboa: CNCDP, 2000 .

FONSECA, Cláudia Damasceno. Arraiais e vilas d'el rei: espaço e poder nas Minas setecentistas. Tradução: Maria Juliana Gambogi Teixeira e Cláudia Damasceno Fonseca. Belo Horizonte: UFMG, 2011. 
GOIS, Diego Marinho de; SOUSA, Eveline Almeida de. Wai-Wai, Tupinambá, Arapiuns: sujeitos/saberes de discentes indígenas da Ufopa (Santarém, Brasil). Revista Estudos Amazônicos, v. XIII, n. 1, p. 181, nota 20, 2015. .; Estudiantes indígenas en la Universidad Federal Del Oeste de Pará (Ufopa), Santarém (Brasil): Wai Wai, Arapium y Tupinambá. Boletín Americanista, Barcelona, ano LXVII, v. 2, n. 75, p. 113-131, 2017.

GOMES, Flávio; SHCWARCZ, Lilia Moritz. Amazônia escravista. In: SHCWARCZ, Lilia Moritz (org.). Dicionário da escravidão e liberdade: 50 textos críticos. São Paulo: Companhia das Letras, 2018.

GRUPIONI, Denise Fajardo. Kaxuyana. In: Povos Indígenas no Brasil, [s. d.]. Disponível em: <https://pib.socioambiental.org/pt/Povo:Kaxuyana.> Acesso em: 29 maio 2019.

HARRIS, Mark. Rebelião na Amazônia: Cabanagem, raça e cultura popular no Norte do Brasil, 1798-1840. Tradução: Gabriel Cambraia Neiva e Lisa Katharina Grund. Campinas: Editora da Unicamp, 2017.

HOLANDA, Sérgio Buarque de. A mineração: antecedentes luso-brasileiros. In: - A época colonial: administração economia e sociedade. História geral da civilização brasileira. 6. ed. São Paulo: Difel, 1985a. t. 1, v. 2, p. 228-258.

- Metais e pedras preciosas. In: HOLANDA, Sérgio Buarque de. A época colonial: administração economia e sociedade. História geral da civilização brasileira. 6. ed. São Paulo: Difel, 1985b. t. 1, v. 2, p. 259-310.

JUSTIÇA do Pará considera etnias Borari e Arapium como índios verdadeiros. Agência Brasil. Brasília, 6 mar. 2015. Disponível em:

$<$ http://agenciabrasil.ebc.com.br/geral/noticia/2015-03/justica-do-paraconsidera-etnias-borari-e-arapium-como-indios-verdadeiros.> Acesso em: 29 maio 2019.

KAXUYANA, Neide Imaya Wara. As trajetórias do povo Kaxuyana no vale do rio Trombetas (1960-2010). 2018. Monografia (Licenciatura em História) - Programa de Ciências Humanas, Universidade Federal do Oeste do Pará, Santarém, 2018. LIMA, Antônio Carlos Souza. O governo dos índios sob a gestão do SPI. In: CUNHA, Manuela Carneiro da (org.). História dos indios no Brasil. [1. ed., 1992]. 2. ed. São Paulo: Companhia das Letras: Secretaria Municipal de Cultura: Fapesp, 2008.

MELATTTI, Julio Cezar. Índios do Brasil. 9 ed. São Paulo: Edusp, 2014. 
MELLO, Evaldo Cabral de. Discurso de posse. Rio de Janeiro: Academia Brasileira de Letras, 27 mar. 2015. Disponível em: < $\underline{w w w . a c a d e m i a . o r g . b r} .>$ Acesso em: 29 maio 2019.

MENÉNDEZ, Miguel A. A área Madeira-Tapajós: situação de contato e relações entre colonizador e indígenas. In: CUNHA, Manuela Carneiro da (org.). História dos índios no Brasil. [1. ed., 1992]. 2. ed. São Paulo: Companhia das Letras: Secretaria Municipal de Cultura: Fapesp, 2008.

MONTEIRO, John Manuel. Negros da terra: índios e bandeirantes na colonização de São Paulo. São Paulo: Companhia das Letras, 1994.

- Tupis, Tapuias e historiadores: estudos de história indígena e do indigenismo. 2001. Tese (Livre-Docência) - Departamento de Antropologia, Universidade Estadual de Campinas, Campinas, 2001.

OLIVEIRA, João Pacheco de; FREIRE, Carlos Augusto da Rocha. A presença indígena na formação do Brasil. Brasília: Ministério da Educação: Museu Nacional, 2006.

PERRONE-MOISÉS, Beatriz. Índios livres e índios escravos: os princípios da legislação indigenista do período colonial (séculos XVI a XVIII). In: CUNHA, Manuela Carneiro da (org.). História dos indios no Brasil. [1. ed., 1992]. 2. ed. São Paulo: Companhia das Letras: Secretaria Municipal de Cultura: Fapesp, 2008.

PHILLIPS, David J. Arapuins. In: Indígenas do Brasil: os primeiros povos do Brasil. 22 set. 2016. Disponível em: < https://brasil.antropos.org.uk/category/ ethnic-profiles/profiles-a/page/3/.> Acesso em: 4 jun. 2020.

RESENDE, Maria Leônia Chaves de. Gentios brasilicos: índios coloniais em Minas Gerais setecentista. 2003. Tese (Doutorado) - Instituto de Filosofia e Ciências Humanas, Universidade Estadual de Campinas, Campinas, 2003.

RICCI, Magda. Do sentido aos significados da Cabanagem: percursos historiográficos. In: ARQUIVO PÚBLICO DO PARÁ. Anais [...]. Belém, 2001. v. 4, p. 241-271.

RODRIGUES, Gefferson Ramos. No sertão, a revolta: grupos sociais e formas de contestação na América portuguesa, Minas Gerais - 1736. 2009. Dissertação (Mestrado em História) - Programa de Pós-Graduação em História Social, Universidade Federal Fluminense, Niterói, 2009.

- Escravos, indios e soldados: povo, política e revolta na América portuguesa no século XVIII (Pernambuco, Minas Gerais e Bahia). 2015. Tese 
(Doutorado) - Instituto de Ciências Humanas e Filosofia, Departamento de História, Universidade Federal Fluminense, Niterói, 2015.

SANTOS, Marcio. Bandeirantes paulistas no sertão do São Francisco: povoamento e expansão pecuária de 1688 a 1734. São Paulo: Edusp, 2009.

SOUZA, Laura de Mello. O sol e a sombra: política e administração na América portuguesa do século XVIII. São Paulo: Companhia das Letras, 2006.

SOUZA JR., José Alves. Competição, rebeldia e dependência: jesuítas, moradores e autoridades na disputa pelo controle e exploração do trabalho indígena na Amazônia colonial. In: SOUZA JR., José Alves. Tramas do cotidiano: religião, política, guerras e negócios no Grão-Pará do Setecentos. Belém: Editora da UFPA, 2012.

VAINFAS, Ronaldo (org.). Dicionário do Brasil colonial (1500-1808). Rio de Janeiro: Objetiva, 2001.

VAZ, Florêncio Almeida. Povos indígenas no Baixo Tapajós querem reconhecimento. In: RICARDO, Beto; RICARDO, Fany (org.). Povos indígenas no Brasil: 2006-2010. São Paulo: Instituto Socioambiental, 2011.

WAI WAI, Denis Teeni. Caminhos para uma universidade aberta aos povos indígenas: análises das dificuldades que os estudantes indígenas Wai Wai vivenciam na Universidade Federal do Oeste do Pará (2015). 2018. Monografia (Licenciatura em História) Programa de Ciências Humanas, Universidade Federal do Oeste do Pará, Santarém, 2018.

. . O processo migratório do povo indígena Wai Wai da Guiana Inglesa para o Brasil através de relatos de história oral. 2018. Projeto de Pesquisa (Licenciatura em História) - Programa de Ciências Humanas, Universidade Federal do Oeste do Pará, Santarém, 2018.

ZEA, Evelyn Schuler. Waiwai. Acrescido de informações dadas por Catherine V. Howard e Carlos Machado Dias Jr. In: Povos Indígenas no Brasil, [s. d.]. Disponível em: < https://pib.socioambiental.org/pt/Povo:Waiwai. $>$ Acesso em: 29 maio 2019. 